\title{
TEC Regional Modeling and Prediction Using ANN Method and Single Frequency Receivers over IRAN
}

\author{
Farideh Sabzehee ${ }^{1}$, Saeed Farzaneh ${ }^{2,}{ }^{*}$, Mohammad Ali Sharifi ${ }^{2}$, Mehdi Akhoondzadeh $^{2}$ \\ ${ }^{1}$ Ph.D. Student of Geodesy Engineering, Faculty of Engineering, University of Isfahan, Iran \\ ${ }^{2}$ School of Surveying and Geospatial Engineering, College of Engineering, University of Tehran, Tehran, Iran
}

\author{
Article history \\ Received October 21, 2016; accepted January 15, 2018. \\ Subject classification: \\ Total Electron Content; Artificial Neural Network; Regional modeling.
}

\begin{abstract}
In order to study in the field of the dynamics and continuous variations in the ionosphere, the ionospheric measurement tools such as ionosondes, incoherent scatter radars, satellites, and Global Positioning System (GPS) networks should be used. Total Electron Content (TEC) is a key parameter in the investigation and identification of ionosphere layer. Observations of dual frequency GPS receivers may lead to extraction of the ionospheric TEC. Global Ionospheric Maps (GIM) are auxiliary Maps for studying ionosphere layer all around the world. Providing the regional TEC map for precise studying of the ionospheric TEC is absolutely essential. Extracting the TEC using dual frequency GPS receivers is carried out by the use of the Bernese software. Regional modeling of ionospheric TEC using Artificial Neural Network (ANN) is a significant domain for predicting the TEC at both single and double frequency GPS receivers. Five locations in Iran were identified and used in the development of an input space and the ANN architecture for the TEC modeling, during the time interval of 20062010. The input space comprises the day number (seasonal variation), the hour (diurnal variation), the sunspot number (a measure of the solar activity) and the magnetic index (a measure of magnetic activity). Based on the obtained results, the ANN shows an acceptable capability and flexibility in modeling and predicting the TEC. The TEC predicted by ANN A (NN TEC) and TEC obtained from the IRI-2012 version of the International Reference Ionosphere (IRI TEC) are compared during equinoxes and solstices. The obtained results show that ANN predicts GPS TEC more accurately than the IRI over Iran. It can be concluded that the IRI-2012 model is not a suitable method for providing the TEC over IRAN.
\end{abstract}

\section{Introduction}

The ionosphere is a region of the upper Earth's atmosphere where there are high concentrations of free ions and electrons. Most of the factors describing the ionospheric variability are interconnected with the sun and its activities under various space weather conditions. Some variations of the ionosphere are predictable such as daily variations, seasonal variations, solar cycle variations (11-year), and 27-day variations. On the contrary, there are also some other unpredictable variations such as sporadic variations.

Electromagnetic signals are delayed when propagating through the ionosphere due to its dispersive nature. The delay occurred in the signal is related to the Total Electron Content (TEC) along the signal path.

If we use dual frequency GPS receivers at two lower-band GPS frequencies, L1 (1575.42 MHz) and L2 $(1227.60 \mathrm{MHz})$, then the electron content of the ionosphere in each considered station will be known and easy to calculate [Hofmann-Wellenhof et al. 1992] TEC describes a projection of the total number of free electrons in a column of one meter squared cross section taken along the signal path extending between two points (i.e. between the satellites and the receiver on the ground) which can be a slant path (STEC) or a vertical path (VTEC).

The TECU indicates the unit of TEC and 1 TECU is equal to 1016 electrons / $\mathrm{m} 2$ [Seeber 2003]. Variations of TEC are functions of many factors such as solar cycle variations, geomagnetic activity effects, diurnal variations, seasonal variations, latitudinal variations (Location), gravitational and seismic activity.

In the past years, ionosondes, inherent scatter radars, Topside sounders and satellites were the major data sources for studying ionosphere layer [Kelley 1989]. Afterwards, empirical and mathematical models were introduced [Klobuchar 1975, Schaer 1999, Bilitza 
2001, Komjathy and Langley 1996, Farzaneh and Forootan 2017]. Nowadays, Global Navigation Satellite Systems (GNSS), like GPS, are widely used for various applications especially research and modeling of the ionosphere using temporal and spatial total electron content (TEC) variations [Meggs 2005, Schaer et al. 1996, Tulunay et al. 2004, 2006, Opperman et al. 2007, Liu et al. 2011].

The ionospheric delay after the selective availability (SA) deactivation is the main source of the systematic error in the navigation systems. The medium of the ionosphere is dispersive and ionospheric refraction depends on the signal frequency and the Total Electron Content (TEC) [Klobuchar 1991].

Several parameters can affect the displacement of the error, namely the hour, the geographic position, the geomagnetic activity and the solar activity [HofmannWellenhof et al. 2001].

Geometry-free combination can eliminate the ionospheric delay of signals only at dual frequency GPS receivers. If a single-frequency GPS receiver is used, deleting the ionospheric delay will be necessary to achieve an accurate navigation. These values of the ionospheric delay can be calculated and eliminated using neural networks or other recommended techniques [Coster et al. 2003, Skone 1998, Komjathy and Langley 1996, Liu and Gao 2003]. Klobuchar ionospheric model is a predicted ionospheric modification model for single frequency GPS users designed to decrease the ionospheric effect by 50\% [Klobuchar 1991, Seeber 2003].

Neural networks as a type of artificial intelligence tools are widely used to describe complicated non-linear input/ output relationships using training data [Cander 1998]. ANN (Artificial Neural Networks) models, compared to mathematical models, are able to learn when the relationship between dependent and independent variables is unknown or very complex or without a priori knowledge of model structure [Mittal et al. 2000, Shene et al. 1998, 1999; Hill et al. 1994, SavkovicStevenovic 1994]. Multi-perceptron neural networks using a back propagation algorithm are very helpful for modeling nonlinear, multivariable, nonparametric and complex phenomena due to their ability to approximate the non-linear function [Rumelhart et al. 1986].

During recent years, the neural networks are applied to predict the ionospheric TEC considering several observed ionospheric parameters such as local times, seasons, longitude, latitude, solar and geomagnetic activities. [Yilmaz et al. 2009, Watthanasangmechai 2012, Leandro and Santos 2007, Ghaffari Razin et al. 2015, Maruyama 2007, El-naggar 2013].

\section{TEC Determination}

\subsection{TEC Extraction from Dual Frequency GPS Data}

The GPS network was constructed from 24 satellites and every four satellites were settled in one plane orbiting the Earth.

Dual frequency GPS receivers record carrier phases $\Phi_{1}, \Phi_{2}$, and codes $\mathrm{P}_{1}, \mathrm{P}_{2}$ observations on both the $\mathrm{L}_{1}$ and $\mathrm{L}_{2}$ frequencies as follows [Seeber 2003, Gao et al. 2002, Barrile et al. 2006, Sharifi and Farzaneh 2017]:

$$
\begin{gathered}
P_{1}=\rho+c .(d t-d T)+d_{\rho}+d_{T}+I_{1}+b_{P 1}^{S}-b_{P 1}^{r}+\varepsilon\left(P_{1}\right) \\
P_{2}=\rho+c .(d t-d T)+d_{\rho}+d_{T}+I_{2}+b_{P 2}^{S}-b_{P 2}^{r}+\varepsilon\left(P_{1}\right) \\
\phi_{1}=\rho+c .(d t-d T)+d_{\rho}+d_{T}+\lambda_{1} N_{1}-I_{1}+b_{\phi 1}^{S}-b_{\phi 1}^{r}+\varepsilon\left(\phi_{\phi_{1}}\right)(3) \\
\phi_{2}=\rho+c .(d t-d T)+d_{\rho}+d_{T}+\lambda_{2} N_{2}-I_{2}+b_{\phi 2}^{S}-b_{\phi 2}^{r}+\varepsilon\left(\phi_{\phi 2}\right)(4)
\end{gathered}
$$

Where $\rho$ is the true geometric range ( $\mathrm{m}$ ) between the satellite and the receiver, $d \rho$ is the orbital error $(\mathrm{m}), \mathrm{c}$ is the speed of light $(3.0 \times 108 \mathrm{~m} / \mathrm{s})$, dt is the satellite clock error with respect to GPS time(s), dT is the receiver clock error with respect to GPS time(s), dT is the tropospheric error(m), $I_{1}$ and $I_{2}$ are the pseudo-range ionospheric delays $(\mathrm{m})$ at $\mathrm{L}_{1}$ and $\mathrm{L}_{2}$ respectively, $b^{S} p_{1}$ and $b^{S} p_{2}$ are the pseudo-range satellite delays $(\mathrm{m})$ at $\mathrm{L}_{1}$ and $\mathrm{L}_{2}$ respectively, $b^{r} p_{1}$ and $b^{r} p_{2}$ are the pseudo-range receiver delays (m) at $\mathrm{L}_{2}$ and $\mathrm{L}_{2}$ respectively, $\varepsilon\left(P_{1}\right)$ and $\varepsilon\left(P_{2}\right)$ are the Pseudo-range measurement noises which include multipath errors $(\mathrm{m}), \lambda_{1}$ and $\lambda_{2}$ are the carrier signal wavelengths at $\mathrm{L} 1$ and $\mathrm{L} 2$ frequencies respectively, $\mathrm{N}_{1}$ and $\mathrm{N}_{2}$ are the carrier phase integer ambiguities, $\mathrm{I}_{1}$ and $\mathrm{I}_{2}$ are the carrier phase ionospheric delays (m), $b^{S} \Phi_{1}$ and $b^{S} \Phi_{2}$ are the carrier phase satellite delays or interfrequency biases $(\mathrm{m})$, $\varepsilon\left(\Phi_{1}\right)$ and $\varepsilon\left(\Phi_{2}\right)$ include the carrier phase measurement noises along with multipath errors with units of meters $(\mathrm{m})$.

The "geometry-free" linear combination is determined using the difference between the pseudo-range measurements or the carrier phase measurements as follows:

$$
P_{2}-P_{1}=I+b_{P}^{S}-b_{P}^{r}
$$

Wherein

$$
I=I_{2}-I_{1}= \pm 40.3 \frac{T E C}{f_{i}^{2}}, b_{P}^{S}=b_{P 1}^{S}-b_{P 2}^{S} b_{P}^{r}=b_{P 1}^{r}-b_{P 2}^{r}
$$

where 40.28 is the constant coefficient. Therefore, TEC is extracted from the geometry-free linear combination as follows [Sharifi and Farzaneh 2016]:

$$
T E C=\frac{1}{40.28}\left(\frac{f_{1}^{2} f_{2}^{2}}{f_{1}^{2}-f_{2}^{2}}\right)\left\{\left(P_{2}-P_{1}\right)-\left(b_{P}^{S}+b_{\mathrm{P}}^{\mathrm{r}}\right)\right\}
$$


TEC can be expressed in its units TECU and 1 TECU is equal to $10^{16}$ electron $/ \mathrm{m} 2$.

Similarly, the TEC can be extracted from the carrier phase measurement using the following equation:

$$
T E C=\frac{1}{40.28}\left(\frac{f_{1}^{2} f_{2}^{2}}{f_{1}^{2}-f_{2}^{2}}\right)\left\{\left(\phi_{2}-\phi_{1}\right)-\left(b_{\phi}^{S}+b_{\phi}^{\mathrm{r}}\right)\right\}
$$

Single-frequency users cannot put down the ionospheric delay straightly but they can decrease the delay using the pre-prepared ionospheric models [Dach et al. 2015].

There are different sources for predicting the total electron content (TEC) i.e. the International Reference Ionosphere (IRI) [Bilitza and Reinisch 2008]. For measuring the ionospheric delays the Klobuchar model can be used whose coefficients are transmitted via the navigation message of the GPS satellite [Klobuchar 1987]. Another method for achieving the total electron content is the Global Ionospheric Maps (GIM) that is available in IGS site. The resolution of these maps is $5^{\circ}$ in longitude and $2.5^{\circ}$ in latitude at 2-hourly intervals (from 00:00 to 00:00 of another day) [Schaer et al. 1998, Wienia 2008, Dow et al. 2009].

\subsection{TEC Estimation Using the Bernese Software}

Global TEC maps have a low precision and resolution which are often imperfect to study or describe detailed features of the regional ionosphere. Therefore, it is required to access regional ionospheric models to get high precision and high resolution of ionospheric corrections. Many models, such as polynomial, grid, and spherical harmonics models have been used to provide regional models [Schaer 1999, Gao et al. 2002, Moon 2004, Sayin et al. 2008, Hirooka et al. 2011].

In this research, the Bernese GPS Software (BGS) is used to calculate the ionospheric TEC values. The TEC maps are initial values in this software. The BGS is a convenient tool for geodetic applications using GNSS systems with a great performance, great accuracy, and numerous flexible reference GPS / GLONASS post-processing package. It can extract several components, e.g., station coordinates, ionospheric (TEC map) and tropospheric delays, orbital parameters, etc.

The TEC maps have been produced with the BGS using PPP program and the output has been delivered in the standard IONEX (IONosphere map EXchange) format [Schaer et al. 1998]. In the BGS, PPP is processed using BPE including data, user scripts, and four process control files (PCF) such as PPP.PCF, RNX2SNX.PCF, BASTST.PCF, CLKDET.PCF.

In this PPP.PCF, regional ionosphere model is pro- duced in IONEX format file using GPS Estimation (GPSEST) program.

The GPSEST is a program with the capability of calculating TEC maps by a geometry-free linear combination from the zero-difference code observations in IONEX [Schaer et al. 1998].

The Global Ionospheric Maps (GIMs) are used in the CODE processing to modify the resolution of the primary carrier phase ambiguities [Rothacher et al. 1996a]. For extracting the TEC values in the vertical direction, the user has to operate modified single-layer mapping function (MSLM). It is assumed that in this single-layer model a shell with an infinitesimal thickness has circumvented the Earth at an altitude, $\mathrm{H}$, of about $450 \mathrm{~km}$ and all the free electrons are laid on it.

Figure 1 demonstrates the fundamental geometry of the MSLM in the sun-fixed coordinate system. The signal transferred from the satellite to the receiver crosses the ionospheric shell known as ionospheric pierce point (IPP).

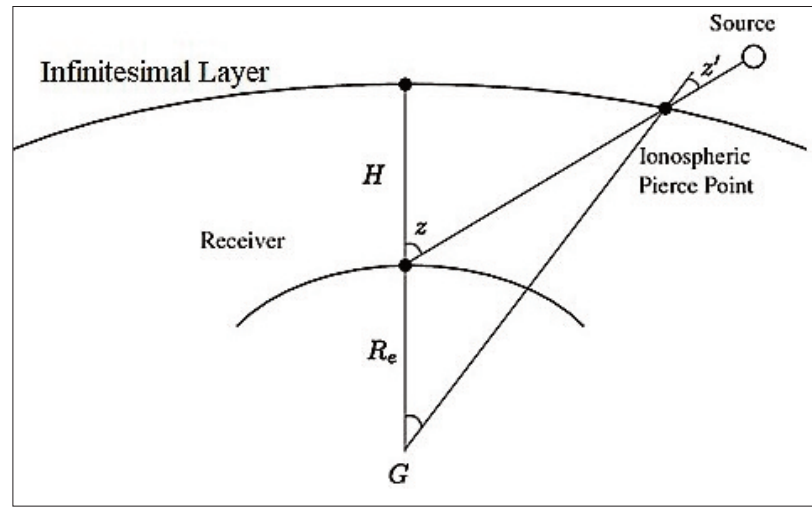

Figure 1. Single-layer Model of the Ionosphere [Modified from Todorova 2008].

The regional TEC maps are generated with the spatial and temporal resolution $0.5^{\circ} \times 0.5^{\circ}$ and 1 hour, respectively using PPP.PCF analysis.

\section{Artificial Neural Networks}

Artificial Neural Network (ANN) is a computational technique when formulating an algorithmic solution for a problem becomes impossible or modeling tools for statistical data is not linear in a case with a lot of samples and the purpose of predicting the future [Fausett 1994, Haykin 1994, Bishop 1995 Barrile et al. 2006].

ANN is made of an interconnected group of artificial neurons working together in harmony to solve non-linear approximations or determine target function and etc.

ANNs behavior has a resemblance to human beings, they learn by samples. ANNs include three main layers namely, input, hidden, and output layers. They are constructed by a number of nodes and weights con- 
necting the nodes. The input data are multiplied by the associated weight of the neuron and a bias is summed with them.

Finally, as can be seen in Figure 2, the production is transmitted to a non-linear filter called activation function (transfer function) to generate the final output.

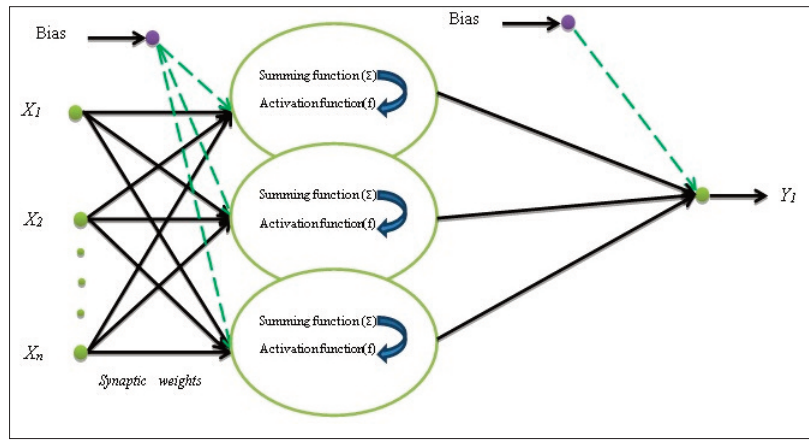

Figure 2. Fundamental Elements of Artificial Neural Network.

The number of neurons and layers can be determined by trial and error in each problem. [Simpson 1990]. The multi-layer feed-forward network [Rumelhart et al. 1986, Haykin 1994] in which the signals go through the network transferring only in a forward direction, start from the input neurons leading to the output ones, hence this network is an acyclic type of network (see Figure 2). ANNs have a number of properties known as problem-solving techniques. ANNs have some important capabilities, namely learning ability, generalization ability, parallel processing, robustness, applicability, and fault-recognition. The activation function, $f$, used in this work is the sigmoid function. The generation equation of the output vector is demonstrated as below:

$$
\begin{gathered}
O=f(w \times x+b) \\
f\left(\left[\begin{array}{llll}
w_{11} & \mathrm{~K} & \mathrm{~K} & w_{1 R} \\
w_{21} & \mathrm{~K} & \mathrm{~K} & w_{2 R} \\
\mathrm{M} & & \mathrm{O} & \mathrm{M} \\
w_{s 1} & \mathrm{~K} & \mathrm{~K} & w_{s R}
\end{array}\right] \times\left[\begin{array}{c}
x_{1} \\
x_{2} \\
\mathrm{M} \\
x_{R}
\end{array}\right]+\left[\begin{array}{c}
b_{1} \\
b_{2} \\
\mathrm{M} \\
b_{s}
\end{array}\right]\right)=\left[\begin{array}{c}
O_{1} \\
O_{2} \\
\mathrm{M} \\
O_{s}
\end{array}\right]
\end{gathered}
$$

In this equation, the values $w_{1}, w_{2}, \ldots . . w_{n}$, are weights of the input vector, $x=\left[x_{1}, x_{2}, \ldots . x_{n}\right]^{T}$, vector $b$ indicates the bias components, $f$ is an activation function and $\mathrm{o}$ is an output vector.

The neurons in each inner layer or hidden layer are called hidden neurons.

\subsection{Input Space to the Neural Network}

Neural Network is an immensely useful tool for nonlinear approximation after training the adequate epochal data [McKinnell and Poole 2000, Habarulema et al. 2007, 2009a; McKinnell 2008].
TEC plays an important role to show the variations of the nonlinear ionospheric predicted by using a neural network [Habarulema et al. 2007, 2009a; Maruyama 2007, Watthanasangmechai et al. 2010, Ratnam et al. 2012, Ghaffari Razin et al. 2015].

Selecting the input space of the neural network is an important stage of the modeling process because the TEC variations depend on the number and type of the chosen parameters. The instances of these variations are seasonal and diurnal variation expressed by the day number (DN) and the hour (HR) respectively.

For data continuity, DN and HR are split into two cyclic trigonometric components or sine and cosine components as follows [McKinnell and Poole 2000, Habarulema et al. 2007, 2009a, McKinnell 2008, Tulunay et al. 2004a and Watthanasangmechai et al. 2010] :

$$
\begin{aligned}
& D N S=\sin \left(\frac{2 \pi D N}{365.25}\right), D N C=\cos \left(\frac{2 \pi D N}{365.25}\right) \\
& H R S=\sin \left(\frac{2 \pi H R}{24}\right), H R C=\cos \left(\frac{2 \pi H R}{24}\right)
\end{aligned}
$$

DNS, DNC, HRS, and HRC are sine and cosine components of DN and HR respectively.

Other inputs of neural network consist of geographical location of the GPS receivers demonstrated by geographic latitudes and longitudes (lat, long), Solar activity and magnetic activity variations shown by a 4month mean of the daily sunspot number (R4) and the mean of the previous eight 3-hourly magnetic A index values (A8) respectively [Habarulema et al. 2007].

Considering a single station showed the reduction of the input space of neural network into seven parameters such as the year number, solar activity (R4), magnetic activity (A8), seasonal variation (DNS and DNC), and diurnal variation (HRS and HRC). Hence, the location of the station is eliminated. Root mean square error (RMSE) and coefficients of determination $\left(\mathrm{R}^{2}\right)$ are comparison indicators of the ANN performance.

Reliability and accuracy of the Neural Networks for modeling the ionospheric TEC are determined by $\mathrm{R}^{2}$ [Drossu and Obradovic 1996] and RMSE as follows:

$$
R^{2}=1-\left[\frac{\sum_{i=1}^{N}\left(T E C_{i(\text { actual })}-T E C_{i(\text { predict })}\right)^{2}}{\sum_{i=1}^{N}\left(T E C_{i(\text { actual })}-\overline{T E C_{(\text {actual })}}\right)^{2}}\right]
$$

$$
R M S E=\left[\frac{\sum_{i=1}^{N}\left(T E C_{i(\text { actual })}-T E C_{i(\text { predict })}\right)^{2}}{N}\right]^{\frac{1}{2}}
$$


Where $\mathrm{N}$ is the number of data points, $\mathrm{TEC}_{\text {actual }}$ is the actual TEC (TEC calculated from GPS observations $\left(\right.$ TEC $\left._{\mathrm{GPS}}\right)$ ) and TEC $_{\text {predict }}$ is the predict TEC (TEC produced by NN (TEC $\mathrm{TN}_{\mathrm{N}}$ ) or IRI-2012 $\left(\right.$ TEC $\left._{\mathrm{IRI}}\right)$ ). Different possible states of the determination coefficient are as follows:

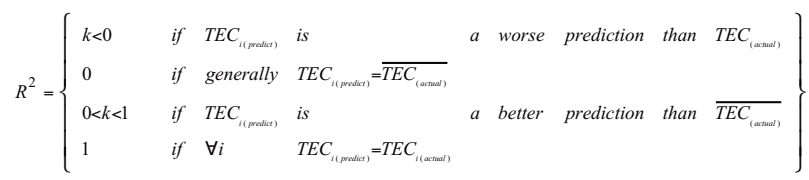

The $\mathrm{R}^{2}$ is the square of the correlation ( $\mathrm{r}$ ) between the predicted TEC produced by NN and the actual TEC obtained by GPS; thus, it varies from 0 to 1 . The $\mathrm{R}^{2}=0$ represents dissimilarity between the dependent variables $\left(\mathrm{TEC}_{\mathrm{NN}}\right.$ or $\left.\mathrm{TEC}_{\mathrm{IRI}}\right)$ and independent variables $\left(\mathrm{TEC}_{\mathrm{GPS}}\right)$ and unpredictability of variables as an aspect of dependency, i.e. dependent variables (TECNN or TEC $_{\text {IRI }}$ ) and independent variable $\left(\mathrm{TEC}_{\mathrm{GPS}}\right)$. On the other hand, $\mathrm{R}^{2}=$ 1 represents the high similarity between the dependent variables $\left(\mathrm{TEC}_{\mathrm{NN}}\right.$ or $\mathrm{TEC}_{\mathrm{IRI}}$ ) and independent variables $\left(\mathrm{TEC}_{\mathrm{GPS}}\right)$ and predictability of variables as an aspect of dependency, i.e. dependent variables $\left(\mathrm{TEC}_{\mathrm{NN}}\right.$ or $\left.\mathrm{TEC}_{\mathrm{IRI}}\right)$ and independent variable ( TEC $_{\mathrm{GPS}}$ ).

If the variance (difference) is low (i.e. the $\mathrm{TEC}_{\mathrm{NN}}$ or $\mathrm{TEC}_{\text {IRI }}$ values are close to the $\mathrm{TEC}_{\mathrm{GPS}}$ value), the $\mathrm{R}^{2}$ will be high and vice versa. Given the $\mathrm{R}^{2}$ parameters or the correlation between $\mathrm{TEC}_{\mathrm{NN}}\left(\mathrm{TEC}_{\mathrm{IRI}}\right)$ and $\mathrm{TEC}_{\mathrm{GPS}}$, interpretation and comparison can be carried out.

Similarly, the relative error is the ratio of the absolute error to GPS TEC [Tulunay et al. 2004, Leandro and Santos 2007, Habarulema et al. 2009a, 2009b; Ghaffari Razin et al. 2015].

The absolute error and relative error are estimated as follows:

$$
\begin{aligned}
& \left|E_{a b s}\right|=\left|T E C_{N N}-T E C_{G P S}\right| \\
& \left|E_{r e l}\right|=\left(\frac{\left|E_{a b s}\right|}{T E C_{G P S}}\right) \times 100 \%
\end{aligned}
$$

$\mathrm{E}_{\mathrm{abs}}$ is the absolute error, $\mathrm{TEC}_{\mathrm{NN}}$ and $\mathrm{TEC}_{\mathrm{GPS}}$ are TEC values predicted by the NN model and calculated from the GPS observations respectively, and $\mathrm{E}_{\text {rel }}$ is the relative error. For determining the relative correction of the NN model, calculating the (100 - $\mid$ Erel $\mid) \%$ parameter will be sufficient. [Tulunay et al. 2004, Leandro and Santos 2007, Habarulema et al. 2009a, 2009b, Ghaffari Razin et al. 2015].

\section{Results and Discussion}

The scope of this paper is regional TEC modeling

\begin{tabular}{|c|c|c|c|c|}
\hline \multirow{2}{*}{ Station } & \multicolumn{2}{|c|}{ Latitude } & \multicolumn{2}{|c|}{ Longitude } \\
\hline & Geographic & eomagne & Geographic & eomagnetic \\
\hline ABADAN & $30.3392^{\circ}$ & $24.67^{\circ}$ & $48.3042^{\circ}$ & $124.62^{\circ}$ \\
\hline TEHRAN & $35.6961^{\circ}$ & $29.49^{\circ}$ & $51.4231^{\circ}$ & $128.54^{\circ}$ \\
\hline RASHT & $37.2808^{\circ}$ & $31.31^{\circ}$ & $49.5831^{\circ}$ & $127.16^{\circ}$ \\
\hline SHIRAZ & $29.6167^{\circ}$ & $23.36^{\circ}$ & $52.5333^{\circ}$ & $128.45^{\circ}$ \\
\hline MASHHAD & $36.3000^{\circ}$ & $29.01^{\circ}$ & $59.6000^{\circ}$ & $136.15^{\circ}$ \\
\hline
\end{tabular}
and predicting the TEC variability. The TEC values ob-
Table 1. Geographic and Geomagnetic Coordinates of the GPS

\begin{tabular}{|c|c|}
\hline Parameter & Option \\
\hline $\mathrm{Rz} 12$ & $\begin{array}{l}\text { Calculated automatically } \\
\text { from the input time }\end{array}$ \\
\hline IG12 & $\begin{array}{l}\text { Calculated automatically } \\
\text { from the input time }\end{array}$ \\
\hline F10_7_DAILY & Calculated in model \\
\hline F10_7_81DAY & Calculated in model \\
\hline TEC_HMAX & $2000 \mathrm{~km}$ \\
\hline Ne_TOP & From NeQuick \\
\hline FPEAK & From URSI \\
\hline F2STORM & on \\
\hline BOTTOM & ABT-2009 \\
\hline F1_PROB & Scotto-1997 no L \\
\hline AURORAL_BOUNDARY & off \\
\hline foE_STORM & on \\
\hline Ne_Dreg & IRI-95 \\
\hline Te_TOP & TBT-2007 \\
\hline IONCOMP & RBV10/TTS03 \\
\hline
\end{tabular}
Receivers.

Table 2. Options of IRI-2012 Model Used in This Research. 

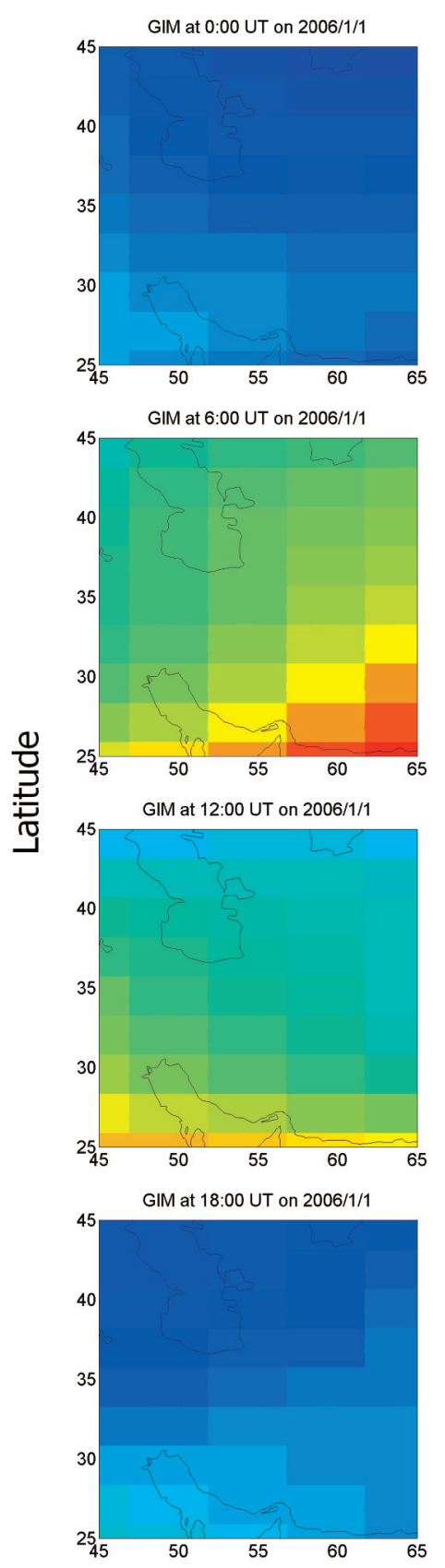

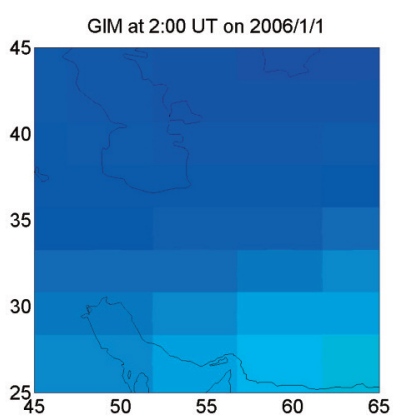

GIM at 8:00 UT on 2006/1/1

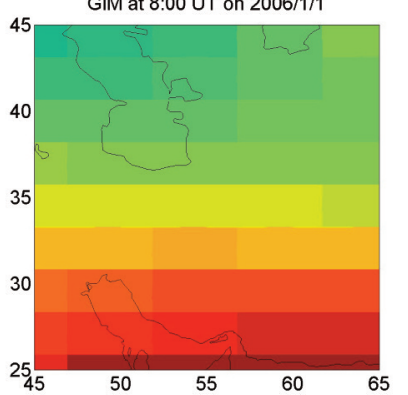

GIM at 14:00 UT on 2006/1/1

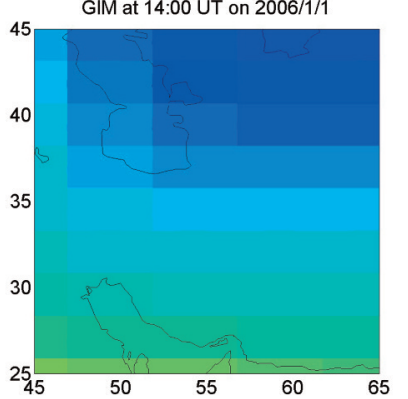

GIM at 20:00 UT on 2006/1/1

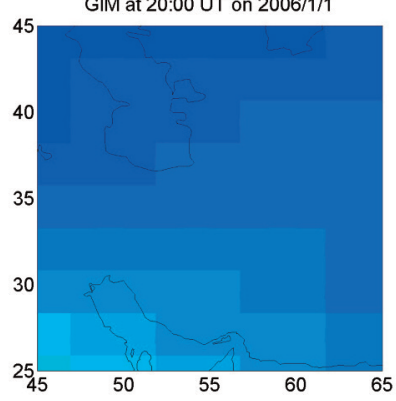

Longitude

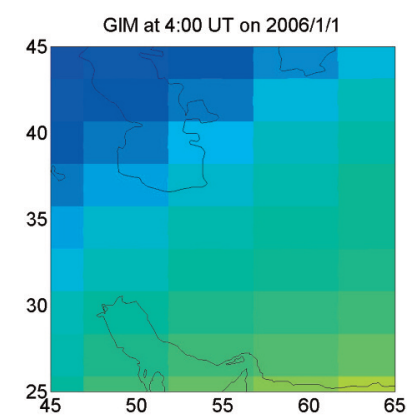

GIM at 10:00 UT on $2006 / 1 / 1$

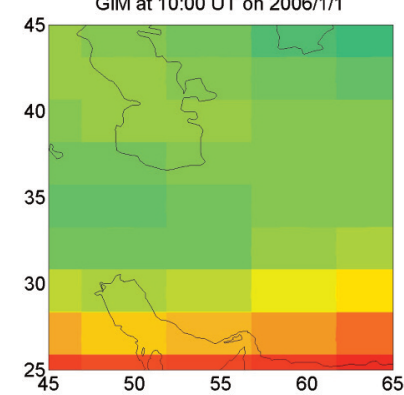

GIM at 16:00 UT on 2006/1/1

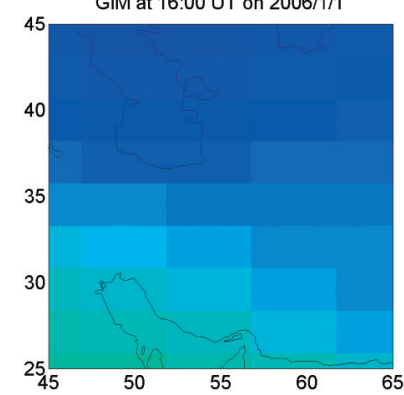

GIM at 22:00 UT on 2006/1/1

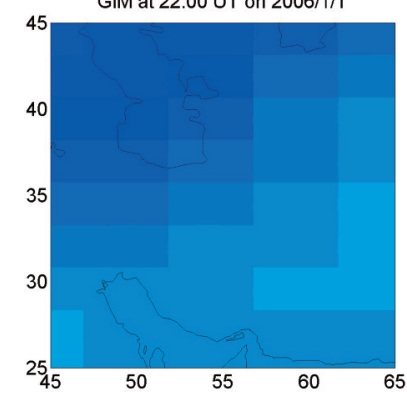

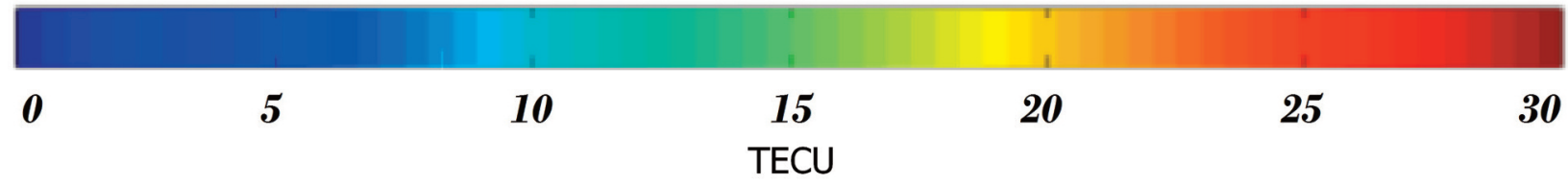

Figure 3. TEC Map from IGS (GIM) over IRAN, January 1, 2006.

tained from GPS were calculated from the dual frequency GPS receiver network over some stations in IRAN such as TEHRAN, MASHHAD, RASHT, ABADAN and SHIRAZ stations using the Bernese software with the spatial and temporal resolutions $0.5^{\circ} \times$ $0.5^{\circ}$ and 1 hour interval respectively.

Table 1 shows the geographical locations for GPS receiver stations over IRAN. In Table 1, geographic and geomagnetic coordinates of each station are determined and the TEC values of them are separately modeled in the following sections.

The minimum and maximum latitudes are related to SHIRAZ and RASHT stations respectively.

For the purpose of this work, hourly values of the TEC were extracted for about four years (2006-2009) in IONEX format file using GPS Estimation (GPSEST) 

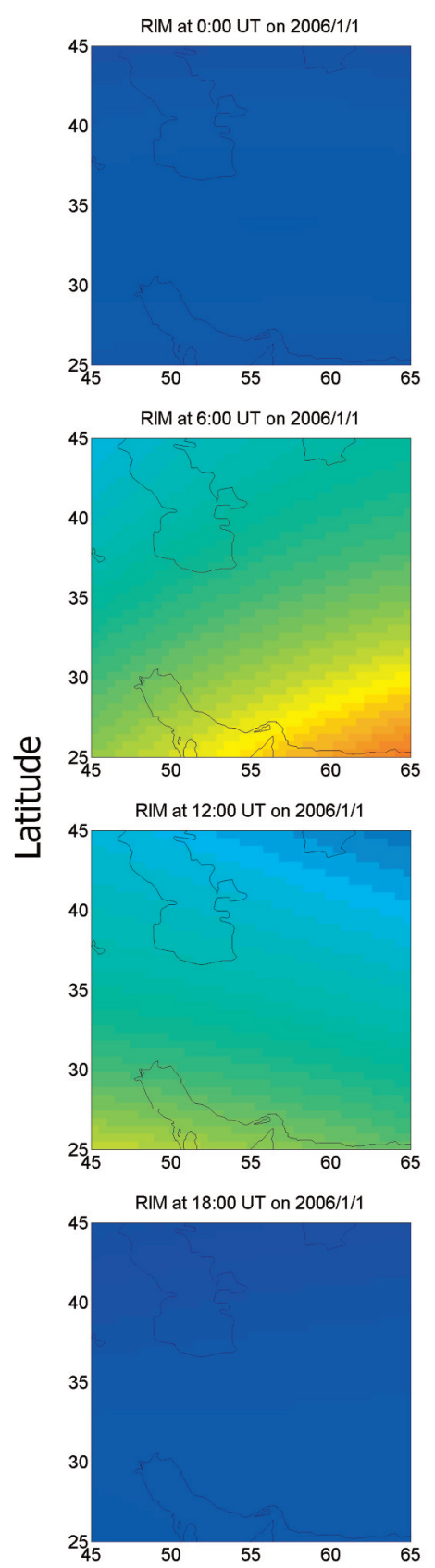

RIM at 2:00 UT on 2006/1/1

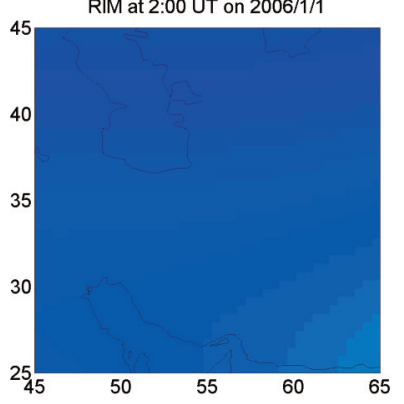

RIM at 8:00 UT on 2006/1/1

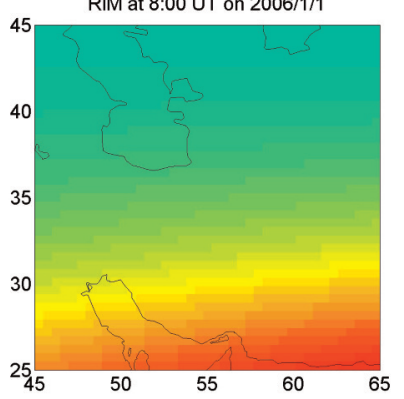

RIM at 14:00 UT on 2006/1/1

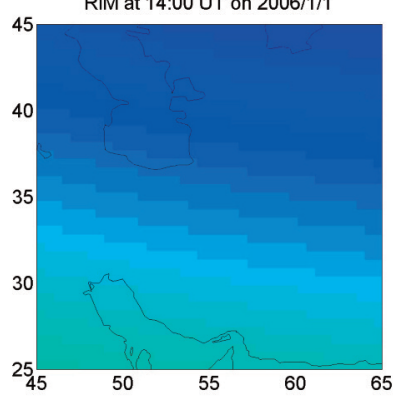

RIM at 20:00 UT on 2006/1/1

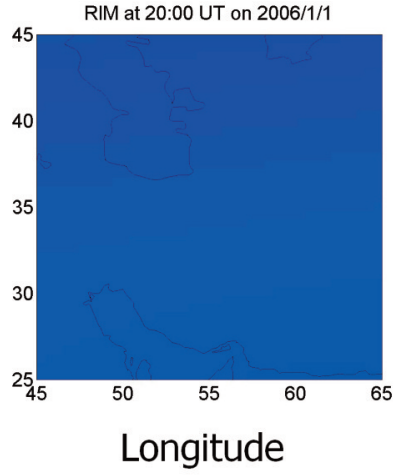

RIM at 4:00 UT on 2006/1/1

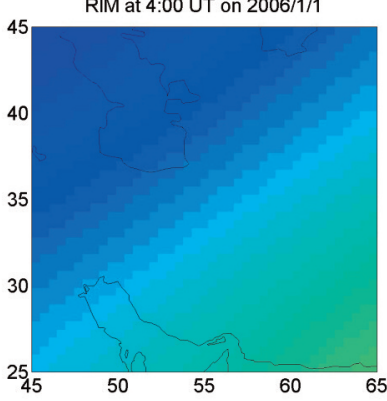

RIM at 10:00 UT on 2006/1/1

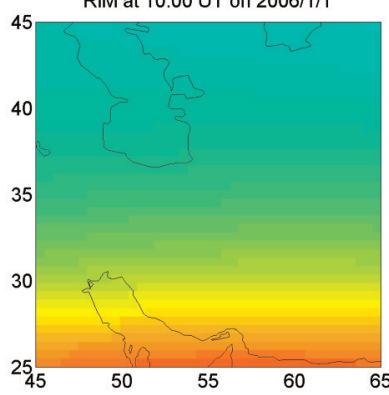

RIM at 16:00 UT on 2006/1/1

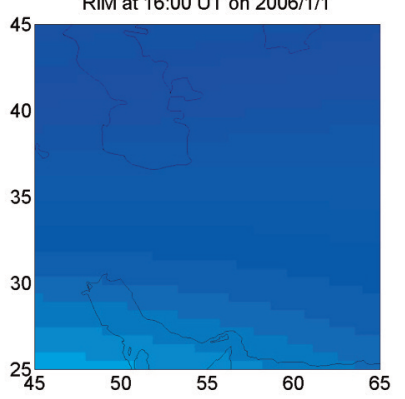

RIM at 22:00 UT on 2006/1/1

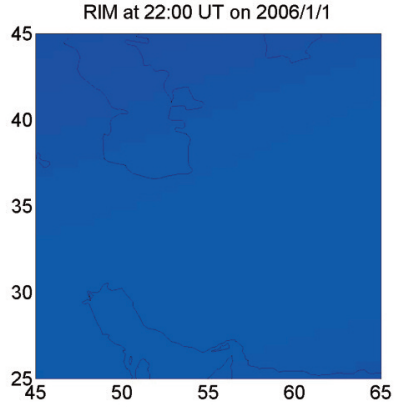

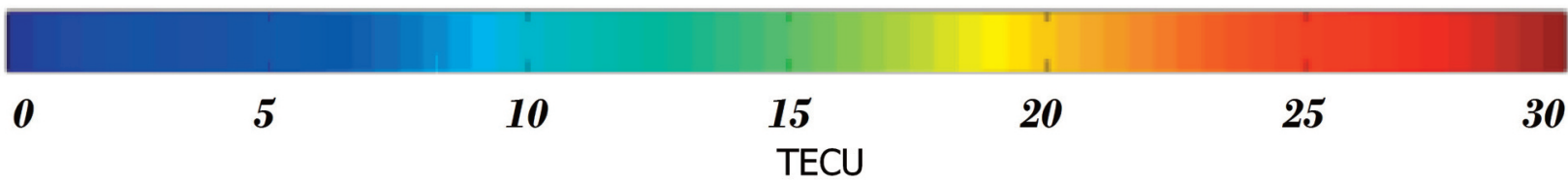

Figure 4. Regional TEC Map (RIM) Produced by BGS over IRAN (GPS Network of 20 Stations from Iranian Permanent GPS Network (IPGN)), January 1, 2006.

program of the Bernese GPS software v5.0. The GPSEST is a program that can calculate the TEC maps using a geometry-free linear combination from the zero-difference code observations in IONEX.

For extracting the TEC values along the vertical direction, $\mathrm{H}$ is assumed to be about $450 \mathrm{~km}$ around the Earth and all the free electrons are laid on it and an el- evation cut-off angle of 15 degrees will be adopted, the receiver IFBs are calculated using the Bernese GPS software v5.0 and the IFB values for the satellite are gained from the Center of the Orbit Determination in Europe (CODE).

The precise orbit files collected by several IGS agencies are interpolated to determine satellite position. 


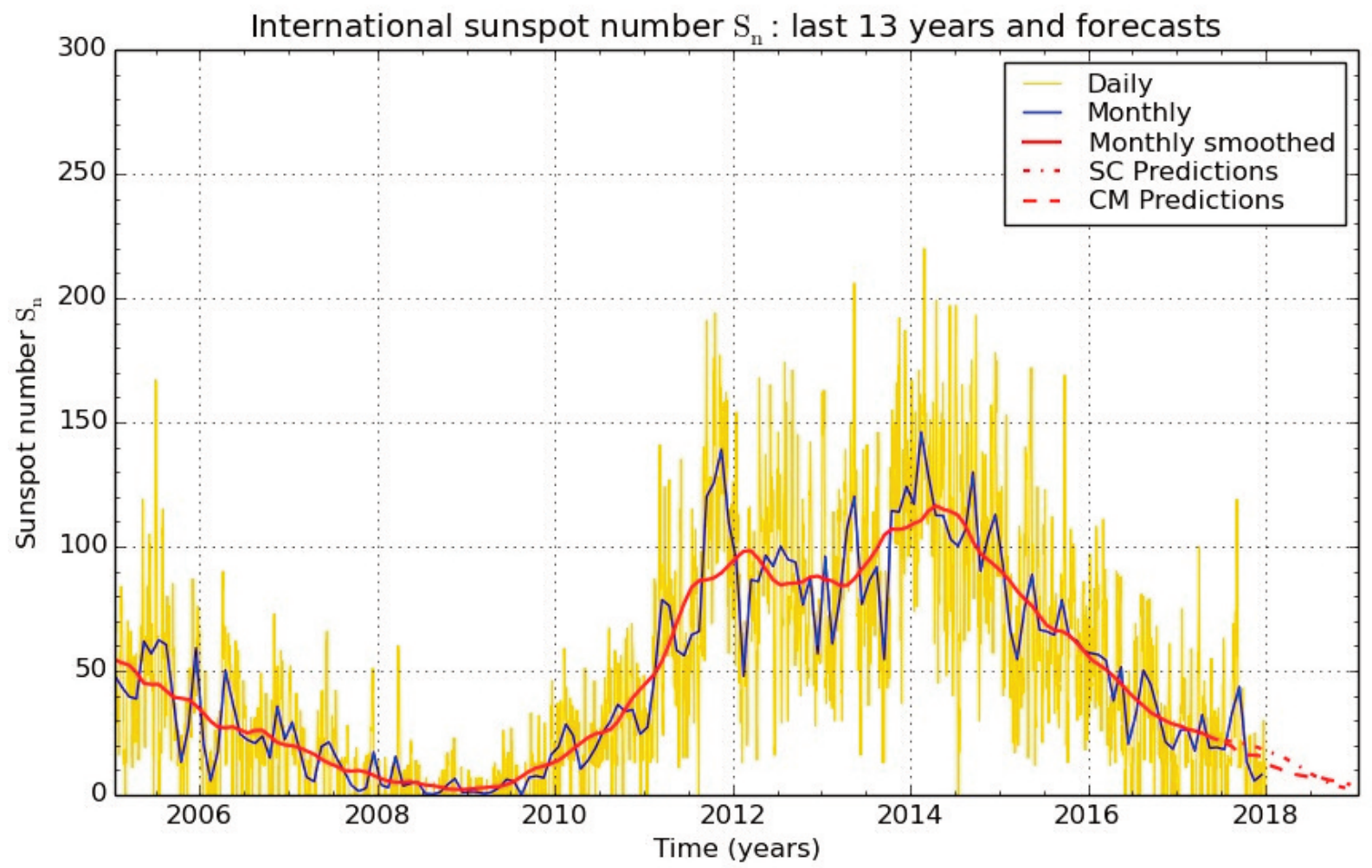

Figure 5. Monthly Averages of Sunspot Numbers Trom 2004 to 2018. Data obtained from (http://sidc.be/silso) Royal Observatory of Belgium 2015 November 1.

Finally, the IRI-2012 is used for testing algorithms. Table 2 shows the specifications of IRI-2012 for this research.

Figure 3 shows Global Ionosphere Map (GIM) in time intervals of 2 hours and the spatial grid of $5^{\circ} \times 2.5^{\circ}$ over IRAN on January 1, 2006 that were captured from the Center of the Orbit Determination in Europe (CODE). Figure 4 shows Regional Ionosphere Map (RIM) in time intervals of 2 hours and the spatial grid of $0.5^{\circ} \times 0.5^{\circ}$ over IRAN on January 1,2006 that were extracted from INX file of the BERNESE software.

The variations of TEC during 24 hours of the day are dependent on the levels of the solar activity. Hence, these variations of TEC during 365 days of the year are dependent on the location, direction, and levels of the solar and geomagnetic activities. Figure 5 shows the low level of the solar activity from 2006 to 2010 (studied period). Figure 6 shows stages of the research from identification to production and the last stage is modeling and statistical analysis.

The input space of the ANN includes the day number (seasonal variation), the hour (diurnal variation), sunspot number (a measure of the solar activity) and magnetic index (a measure of magnetic activity).

Variations of TEC are the function of many factors such as solar cycle variations, geomagnetic activity effects, diurnal variations, seasonal variations, latitudinal variations (Location), gravitational and seismic activity.
Consideration of a single station showed the reduction of the input space of the neural network into seven parameters, namely the year number, solar activity (R4), magnetic activity (A8), seasonal variation (DNS and DNC) and diurnal variation (HRS and HRC). Hence, the location of the station was eliminated.

In this study, the architecture of the neural network consists of one input layer with seven parameters, one hidden layer with fifty neurons and one output layer with one neuron.

In this work, the main purpose is to model iono-

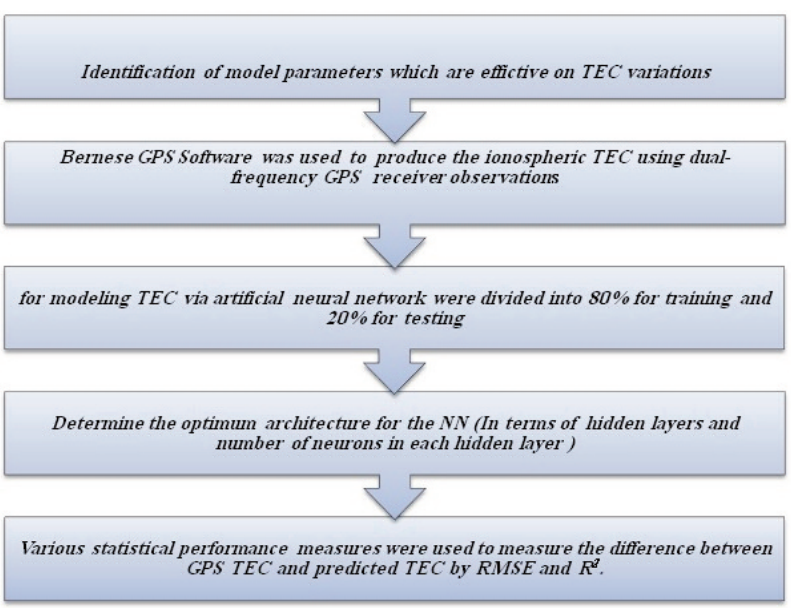

Figure 6. A Flowchart of the TEC Modeling Scheme in This Work. 


\begin{tabular}{lccc}
\hline Station & $\begin{array}{c}\text { Correlation } \\
\text { coefficient }\end{array}$ & RMSE & $\mathbf{R}^{2}$ \\
\hline ABADAN & 0.994 & 0.7139 & 0.9718 \\
TEHRAN & 0.992 & 0.6029 & 0.97 \\
RASHT & 0.992 & 0.6512 & 0.9633 \\
SHIRAZ & 0.994 & 0.7269 & 0.9760 \\
MASHHAD & 0.992 & 0.6107 & 0.9662 \\
\hline
\end{tabular}

Table 3. Evaluation of Produced Models for Each Station.

spheric TEC by NN (the NN application for predicting the TEC over several stations in IRAN (see Table 1)) and compare predicted $\mathrm{TEC}_{\mathrm{NN}}$ with $\mathrm{TEC}_{\mathrm{GPS}}$ and TEC values obtained using the IRI-2012 version of the International Reference Ionosphere (IRI). ues which are less than 1 TECU (see Table 3).

The important days in 2010 consisted of Vernal equinox (March 20), Summer solstice (June 21), Autumnal equinox (September 22) and Winter solstice (December 21).

Table 4 indicates the RMSE and $\mathrm{R}^{2}$ values between the GPS TEC and TEC values predicted by the NN and IRI-2012 models for equinox and solstice days in 2010 over TEHRAN station.

The NN model predicts TEC more precisely during all seasons than the IRI-2012 model.

The NN model provides a more accurate prediction during the autumnal equinox (September 22) in comparison with other days. The $\mathrm{R}^{2}$ values and the RMSE values of the neural network are higher and less than 1 TECU during equinoxes and solstices respectively (Table 4).

On the other hand, the IRI model predicts TEC very low resolution during all seasons because the R2 values and the average of RMSE values are zero and

Date $\quad$ Neural Network(NN) IRI Model

\begin{tabular}{|c|c|c|c|c|}
\hline & RMSE $_{\mathrm{NN}}($ TECU) & $\mathrm{R}_{\mathrm{NN}}^{2}$ & RMSE $_{\text {IRI }}($ TECU) & $\mathrm{R}_{\text {IRI }}^{2}$ \\
\hline 2010 Mar 20 & 0.5956 & 0.9147 & 4.1179 & 0 \\
\hline 2010 Jun 21 & 0.9193 & 0.8747 & 5.7346 & 0 \\
\hline 2010 Sept 22 & 0.3750 & 0.9290 & 4.8456 & 0 \\
\hline 2010 Dec 21 & 0.4097 & 0.9117 & 3.8468 & 0 \\
\hline
\end{tabular}

Table 4. Root Mean Square Error (RMSE) and Coefficient of Determination (R2) Between IRI Model and Neural Network, Calculated over TEHRAN Station for Each of the Four Days Representing Equinoxes and Solstices in 2010.

In this paper, the dataset is divided into training and testing sets. The training dataset is the TEC data in 2006 - 2009 time interval while the TEC data in 2010 is reserved for the testing process.

Table 3 shows a summary of the correlation coefficient, RMSE and $\mathrm{R}^{2}$ between TECGPS and TECNN over each of the five stations during the training period of neural network model. As shown in Table 3, the $\mathrm{R}^{2}$ values are high and there is the goodness of fit of a statistical model between TEC produced by the neural network and TEC determined by GPS observations (the $\mathrm{R} 2$ values are very close to 1 ) as well as the RMSE val-
4.6362 TECU respectively (Table 4).

There is a fact that the International Reference Ionosphere (IRI) is a monthly median model [Bilitza et al., J. Geodesy 85, 909-920, 2011] and can not correspond toTEC of a specific day. Thus, according to equation (13), the numerator and denominator of the fraction are equalized $\left(\mathrm{TEC}_{\mathrm{i} \text { (predict) }}=\overline{\mathrm{TEC}}(\right.$ (actual) $)$. As a result

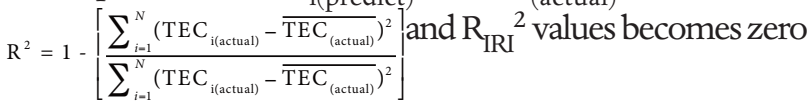

In Table 5, the absolute error is defined as the magnitude of the difference between the TEC predicted by NN model and the GPS TEC. 
TEC calculated from GPS Obsevations

\begin{tabular}{|c|c|c|c|c|c|c|}
\hline & Correlation $(\%)$ & $\mathrm{E}_{\text {real }}(\%)$ & Std & $\operatorname{Mean}($ TEC) & Std & $\operatorname{Mean}(T E C)$ \\
\hline 2010 Mar 20 & 95.32 & 4.68 & 2.23 & 8.79 & 2.08 & 8.39 \\
\hline 2010 Sept 22 & 96.65 & 3.35 & 1.48 & 8.71 & 1.43 & 8.60 \\
\hline 2010 Jun 21 & 95.32 & 4.68 & 2.93 & 16.26 & 2.65 & 16.38 \\
\hline 2010 Dec 21 & 95.80 & 4.19 & 1.44 & 7.84 & 1.40 & 7.84 \\
\hline
\end{tabular}

Table 5. Comparison of GPS TEC with TEC Predictions from NN Model over TEHRAN During Equinoxes such as March 20, September 22 and Solstices such as June 21, December 21; all in 2010.

In Table 5, TEC predicted by NN and TEC produced by GPS are compared over TEHRAN station during equinoxes and solstices in 2010.

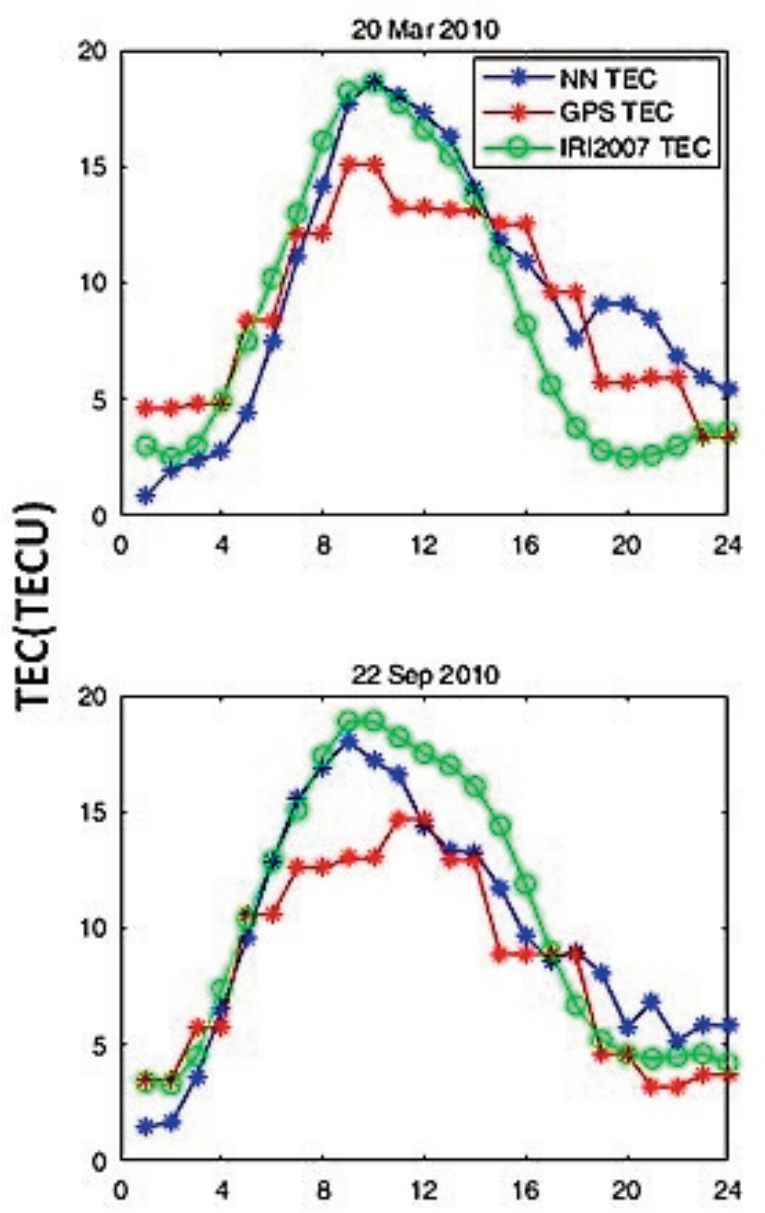

Correlation coefficients give reliability confidence levels of the NN model to predict GPS TEC. As shown in Table 5, correlation coefficients are greater than $95 \%$
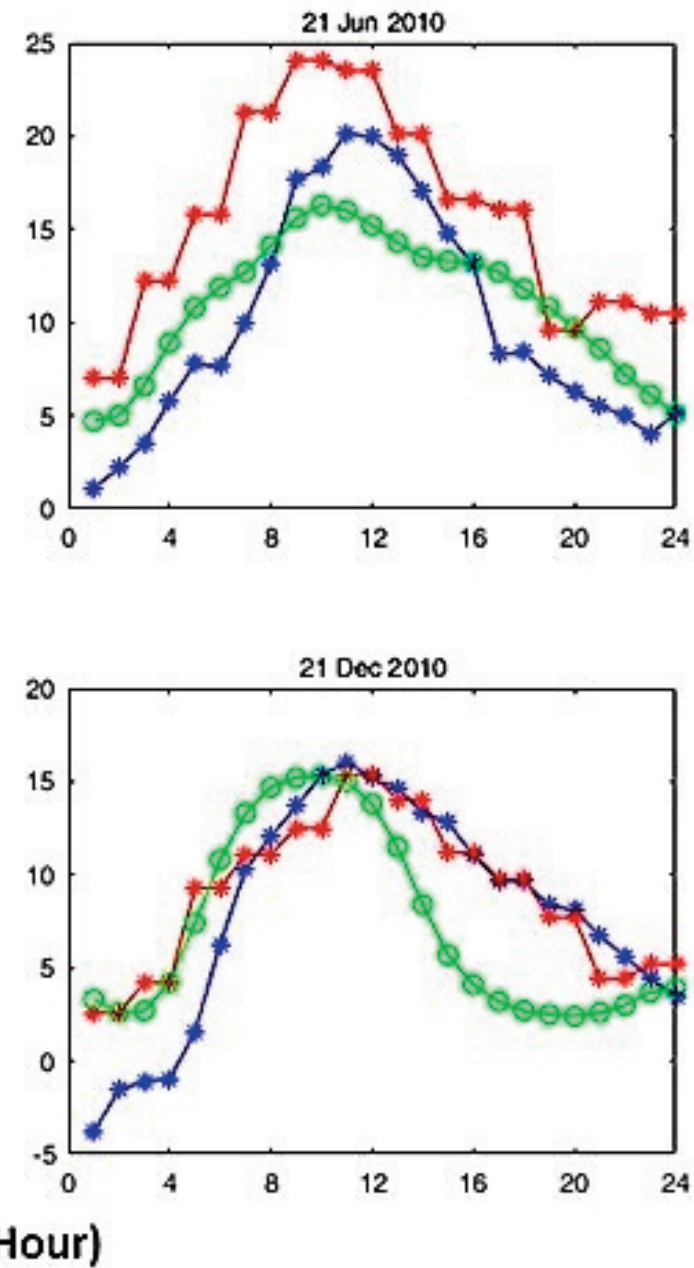

Figure 7. GPS TEC, NN Predicted TEC and IRI-2012 TEC for Important Days of 2010 from 01:00 UT to 24:00 UT over TEHRAN Station. 

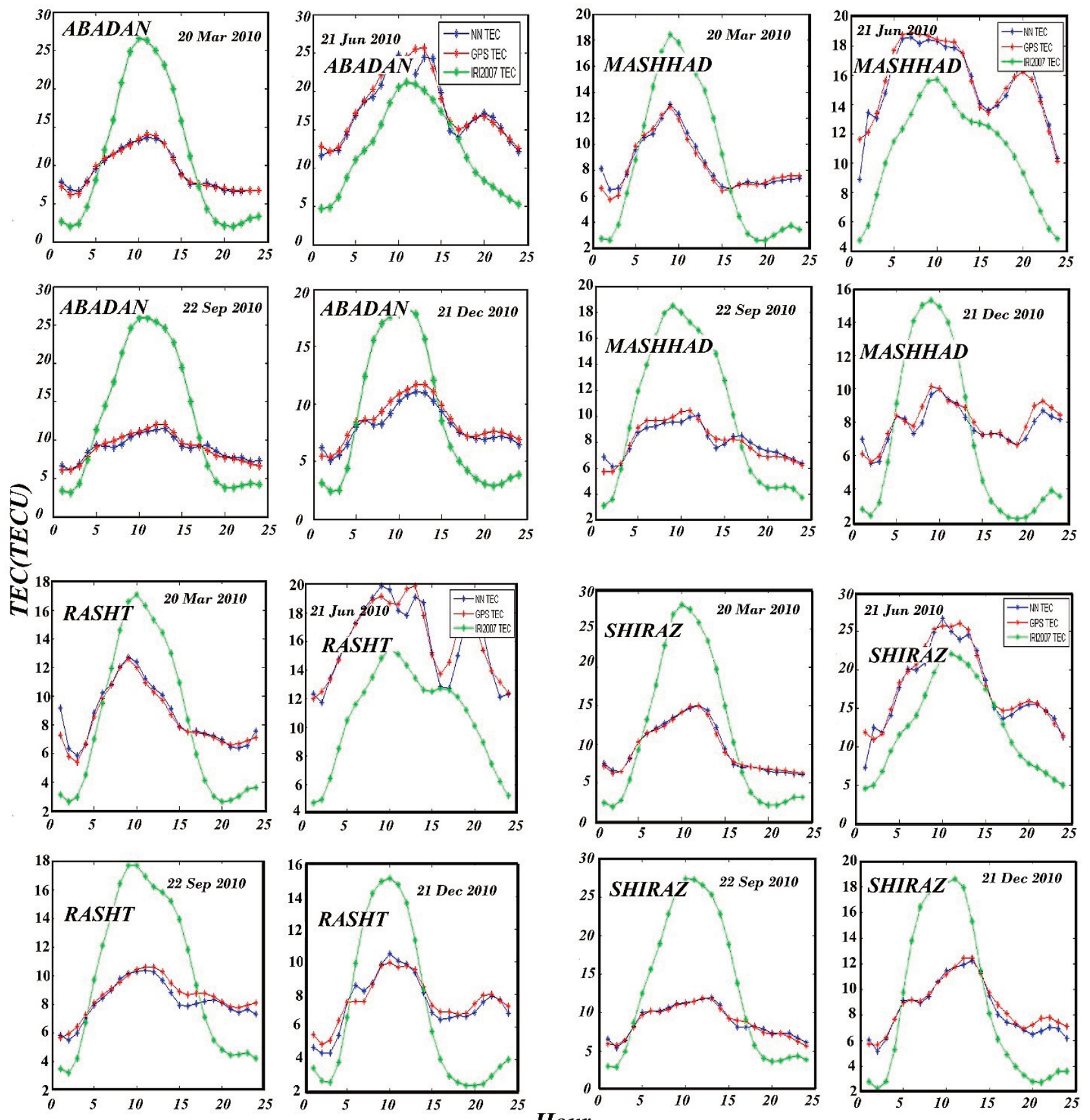

Figure 8. GPS TEC, NN Predicted TEC and IRI TEC for Important Days of 2010 from 01:00 UT to 24:00 UT over ABADAN, MASHHAD, RASHT and SHIRAZ Stations.

and the maximum value for the correlation coefficient belongs to September 22. Similarly, the minimum relative error is $3.35 \%$ for September 22 . A relative error of $4.68 \%$ expresses that the NN can predict TEC with the possibility of $95.32 \%$ for March 20 and June 21 . Finally, an average relative error during equinoxes and solstices in 2010 over TEHRAN is $4.22 \%$ indicating the approximate determination of this NN model for about $95.77 \%$ of the GPS TEC on average.

As expected, TEC produced by the IRI-2012 model is higher than GPS TEC because there is no global GPS station over IRAN at the determination of TEC using 
FARZANEH ET AL.

\begin{tabular}{|c|c|c|c|c|}
\hline \multicolumn{5}{|c|}{ RASHT } \\
\hline \multirow[t]{2}{*}{ Date } & \multicolumn{2}{|c|}{ Neural Network(NN) } & \multicolumn{2}{|c|}{ IRI Model } \\
\hline & RMSE $_{N N}(T E C U)$ & $\mathrm{R}_{\mathrm{NN}}^{2}$ & RMSE $_{\text {IRI }}($ TECU) & $\mathrm{R}_{\text {IRI }}^{2}$ \\
\hline 2010 Mar 20 & 0.4678 & 0.9479 & 3.5632 & 0 \\
\hline 2010 Jun 21 & 0.8961 & 0.8695 & 5.6599 & 0 \\
\hline 2010 Sept 22 & 0.4472 & 0.8886 & 4.4892 & 0 \\
\hline 2010 Dec 21 & 0.4862 & 0.8754 & 3.5228 & 0 \\
\hline \multicolumn{5}{|c|}{ MASHHAD } \\
\hline \multirow[t]{2}{*}{ Date } & \multicolumn{2}{|c|}{ Neural Network(NN) } & \multicolumn{2}{|c|}{ IRI Model } \\
\hline & $\operatorname{RMSE}_{\mathrm{NN}}(\mathrm{TECU})$ & $\mathrm{R}_{\mathrm{NN}}^{2}$ & RMSE $_{\text {IRI }}($ TECU) & $\mathbf{R}_{\text {IRI }}^{2}$ \\
\hline 2010 Mar 20 & 0.4444 & 0.9540 & 4.0521 & 0 \\
\hline 2010 Jun 21 & 0.7547 & 0.9143 & 5.0890 & 0 \\
\hline 2010 Sept 22 & 0.4550 & 0.9039 & 5.0068 & 0 \\
\hline 2010 Dec 21 & 0.4568 & 0.8568 & 4.2892 & 0 \\
\hline \multicolumn{5}{|c|}{ ABADAN } \\
\hline \multirow[t]{2}{*}{ Date } & Neural Network(NN) & & IRI Model & \\
\hline & $\operatorname{RMSE}_{\mathrm{NN}}(\mathrm{TECU})$ & $\mathrm{R}_{\mathrm{NN}}^{2}$ & RMSE $_{\text {IRI }}($ TECU) & $\mathbf{R}_{\text {IRI }}^{2}$ \\
\hline 2010 Mar 20 & 0.2719 & 0.9896 & 6.9332 & 0 \\
\hline 2010 Jun 21 & 1.0140 & 0.9468 & 5.8142 & 0 \\
\hline 2010 Sept 22 & 0.4885 & 0.9304 & 8.3489 & 0 \\
\hline 2010 Dec 21 & 0.5624 & 0.9091 & 4.7026 & 0 \\
\hline \multicolumn{5}{|c|}{ SHIRAZ } \\
\hline \multirow[t]{2}{*}{ Date } & \multicolumn{2}{|c|}{ Neural Network(NN) } & \multicolumn{2}{|c|}{ IRI } \\
\hline & $\operatorname{RMSE}_{\mathrm{NN}}(\mathrm{TECU})$ & $\mathrm{R}_{\mathrm{NN}}^{2}$ & RMSE $_{\text {IRI }}($ TECU) & $\mathrm{R}_{\text {IRI }}^{2}$ \\
\hline 2010 Mar 20 & 0.2882 & 0.9912 & 6.9081 & 0 \\
\hline 2010 Jun 21 & 1.2627 & 0.9360 & 5.4157 & 0 \\
\hline 2010 Sept 22 & 0.3435 & 0.9709 & 8.5183 & 0 \\
\hline 2010 Dec 21 & 0.4633 & 0.9453 & 4.4476 & 0 \\
\hline
\end{tabular}

Table 6. Root Mean Square Error and Coefficient of Determination between IRI Model and Neural Network are Calculated for Important Days in 2010.

IRI-2012 model.

Therefore the IRI-2012 model is not fit and efficient for determining TEC over IRAN because the IRI model is median and cannot be always corresponding to TEC of a specific day. According to the graphical representation of TEC (from 01:00 UT to 24:00 UT) from three different models in Figure 7 and correlation coefficients values in Table 5, the high-performance neural network was obtained.

TEC predicted by the neural network is very simi- lar and close to TEC produced by GPS at four stations (see Figure 8).

The separation between NN TEC and GPS TEC in the autumnal equinox (Sept 22), vernal equinox (Mar 20) and winter solstice (Dec 21) are very low and NN TEC is predicted with extremely high precision, but the greatest difference is observed in the summer solstice (June 21) and the prediction of NN TEC has lower precision (standard deviation (Std) is high, see Table 7). It can also be observed from Tables 6 and 7 that the RMSE 


\begin{tabular}{|c|c|c|c|c|c|c|}
\hline \multicolumn{7}{|c|}{ RASHT } \\
\hline \multirow[t]{2}{*}{ Date } & \multicolumn{4}{|c|}{ TEC produced by NN } & \multicolumn{2}{|c|}{ TEC produced by GPS } \\
\hline & Correlation(\%) & $\mathrm{E}_{\text {real }}(\%)$ & Std & $\operatorname{Mean}($ TEC) & Std & $\operatorname{Mean}(\mathrm{TEC})$ \\
\hline 2010 Mar 20 & 96.41 & 3.58 & 2.13 & 8.60 & 2.09 & 8.37 \\
\hline 2010 Sept 22 & 95.26 & 4.73 & 1.38 & 8.21 & 1.36 & 8.54 \\
\hline 2010 Jun 21 & 95.60 & 4.39 & 2.74 & 15.94 & 2.53 & 16.11 \\
\hline 2010 Dec 21 & 93.85 & 6.14 & 1.73 & 7.48 & 1.40 & 7.64 \\
\hline \multicolumn{7}{|c|}{ MASHHAD } \\
\hline \multirow[t]{2}{*}{ Date } & \multicolumn{4}{|c|}{ TEC Produced by NN } & \multicolumn{2}{|c|}{ TEC Produced by GPS } \\
\hline & Correlation(\%) & $\mathrm{E}_{\text {real }}(\%)$ & Std & Mean(TEC) & Std & Mean(TEC) \\
\hline 2010 Mar 20 & 95.91 & 4.08 & 2.05 & 8.48 & 2.11 & 8.35 \\
\hline 2010 Sept 22 & 95.12 & 4.87 & 1.21 & 8.03 & 1.49 & 8.05 \\
\hline 2010 Jun 21 & 96.09 & 3.90 & 2.66 & 15.45 & 2.63 & 15.59 \\
\hline 2010 Dec 21 & 95.52 & 4.47 & 1.13 & 7.77 & 1.23 & 8.00 \\
\hline \multicolumn{7}{|c|}{ ABADAN } \\
\hline \multirow[t]{2}{*}{ Date } & \multicolumn{4}{|c|}{ TEC Produced by NN } & \multicolumn{2}{|c|}{ TEC Produced by GPS } \\
\hline & Correlation(\%) & $\mathrm{E}_{\text {real }}(\%)$ & Std & Mean(TEC) & Std & Mean(TEC) \\
\hline 2010 Mar 20 & 97.36 & 2.63 & 2.64 & 9.23 & 2.72 & 9.22 \\
\hline 2010 Sept 22 & 95.18 & 4.81 & 1.55 & 8.81 & 1.89 & 8.88 \\
\hline 2010 Jun 21 & 95.94 & 4.05 & 4.35 & 17.61 & 4.49 & 18.00 \\
\hline 2010 Dec 21 & 93.81 & 6.18 & 1.72 & 8.01 & 1.90 & 8.44 \\
\hline \multicolumn{7}{|c|}{ SHIRAZ } \\
\hline \multirow[t]{2}{*}{ Date } & \multicolumn{4}{|c|}{ TEC produced by NN } & \multicolumn{2}{|c|}{ TEC produced by GPS } \\
\hline & Correlation(\%) & $\mathrm{E}_{\text {real }}(\%)$ & Std & $\operatorname{Mean}(\mathrm{TEC})$ & Std & $\operatorname{Mean}($ TEC $)$ \\
\hline 2010 Mar 20 & 97.45 & 2.54 & 3.26 & 9.45 & 3.14 & 9.41 \\
\hline 2010 Sept 22 & 96.68 & 3.31 & 2.04 & 8.79 & 2.05 & 8.71 \\
\hline 2010 Jun 21 & 93.61 & 6.38 & 5.18 & 17.43 & 5.09 & 17.86 \\
\hline 2010 Dec 21 & 95.25 & 4.74 & 2.15 & 8.45 & 2.02 & 8.72 \\
\hline
\end{tabular}

Table 7. Comparison of GPS TEC with TEC Predictions from NN Model During Equinoxes such As March 20, September 22 and Solstices such as June 21, December 21; all in 2010

of the modeled ionospheric is approximately less than 1 TECU.

As can be seen from Table 8 , the minimum value of the RMSE is related to the spring season at the RASHT station in the highest latitude and the maximum value of the RMSE is related to the winter season at the SHIRAZ station in the lowest latitude.

By choosing several stations with different latitudes, it was concluded that the values of TEC for stations with lower latitudes and closer to the equator are larger than stations with higher latitudes.

As shown in Figure 9, TEC values during January 1, 2006, over TEHRAN, RASHT, MASHHAD, ABADAN and SHIRAZ stations with different latitudes are compared.

The results obtained from this graph showed that, firstly, all stations have the maximum of TEC at 12.30 LT (9 UT+3.30=12.30 LT). At the early hours of the day, the TEC values increase gradually and at the midday, it reaches its maximum value (due to high activity of the 


\begin{tabular}{|c|c|c|c|c|c|c|}
\hline \multicolumn{7}{|c|}{ RMSE(TECU) } \\
\hline & SHIRAZ & ABADAN & MASHHAD & RASHT & TEHRAN & Mean \\
\hline Spring & 0.6467 & 0.6204 & 0.5370 & 0.5133 & 0.52 & 0.56748 \\
\hline Summer & 0.6760 & 0.6812 & 0.5933 & 0.6793 & 0.5614 & 0.63824 \\
\hline Autumn & 0.6358 & 0.6546 & 0.5381 & 0.6320 & 0.5748 & 0.60706 \\
\hline Winter & 0.7045 & 0.6771 & 0.5913 & 0.6190 & 0.6065 & 0.63968 \\
\hline Mean & 0.6657 & 0.6583 & 0.5649 & 0.6109 & 0.5656 & \\
\hline
\end{tabular}

Table 8. Comparison of Monthly Mean Variation of TEC at Different Seasons for Several Stations During 2006.

sun). Afterwards, the TEC values decrease. Secondly, Figure 9 shows that the first and the second maximum amount of TEC is related to SHIRAZ and ABADAN station respectively, and the minimum amount of TEC is related to RASHT station (the distance of the station from the equator is important). primarily dependent on the position of the station with respect to the magnetic equator.

The monthly mean TEC from January to November 2006 is shown in Figure 10 for two selected stations; RASHT station (lower latitude), and SHIRAZ station (higher latitude).

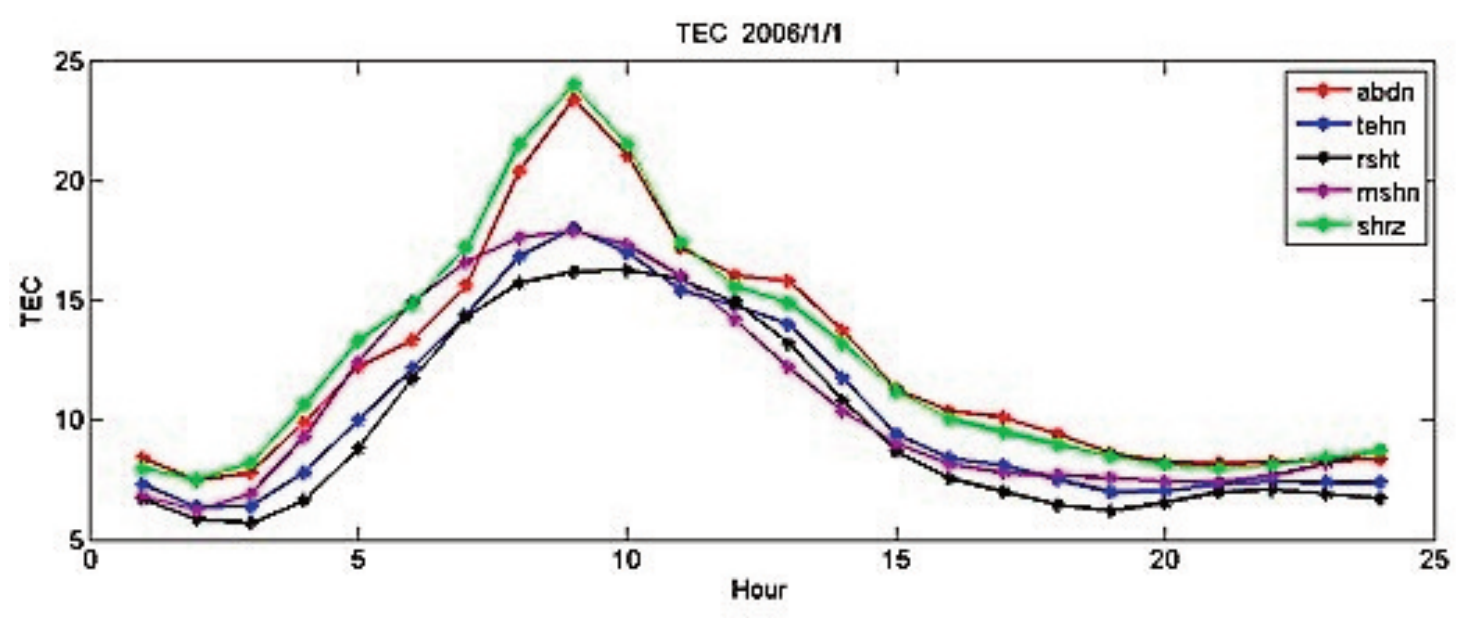

Figure 9. Comparison Values of TEC at Different Stations with Different Latitudes during January 1, 2006.

One of the important parameters of the variation ionospheric TEC values is the geographic position (especially latitude). Therefore, at lower latitudes (latitude of SHIRAZ is $29.6^{\circ}$ ) and near the equator line, solar activities are more effective in comparison with the higher latitudes. The increase in ionization rate makes an increase in electron density and TEC of the ionosphere.

RASHT station in comparison with other stations is located at a higher latitude and it has less TEC value. Consequently, increasing latitude will decrease the TEC value.

It can be perceived that characteristics of TEC are
In spring seasons (April), the TEC values are maximum and in December (winter), they are minimum. From winter to spring, the TEC values are increased but from spring to summer, and summer to autumn, the ionospheric TEC values are decreased (see Figure 10,11). During the April, May, and June, the TEC values are maximum in comparison with the other months.

The average of all graphs concerning the special hours in Figure 10.a is shown in Figure 11. Basically, during a day, the mean TEC values are minimum in the early morning (Before the dawn) and at night, and they are maximum at midday (due to the level of the 

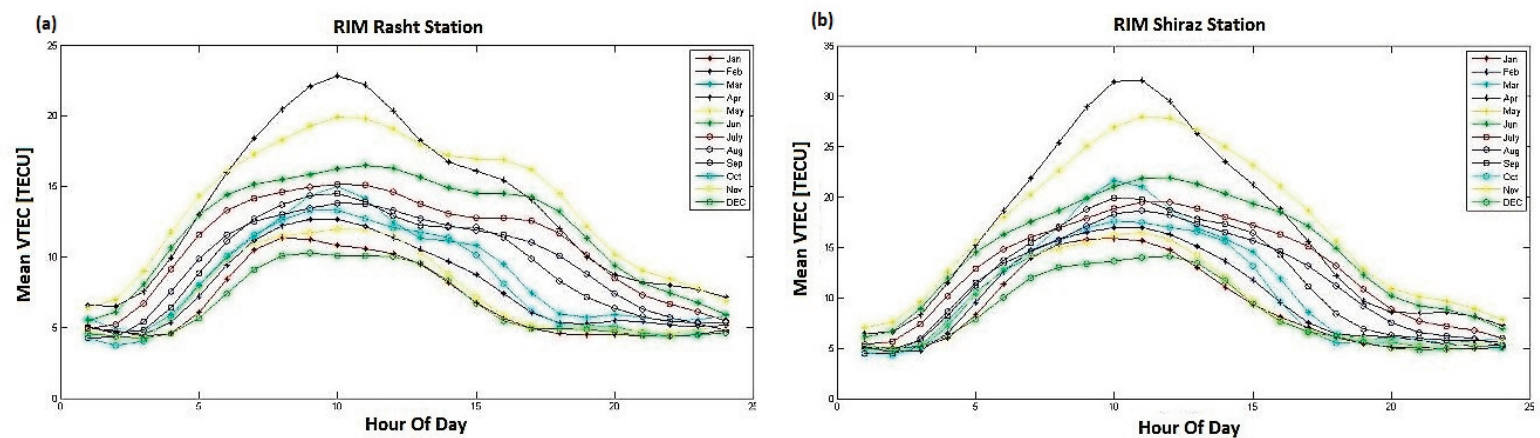

Figure 10. Comparison of Monthly Mean Variation of TEC at RASHT Station (a) and SHIRAZ Station (b) from January to December, 2006.

solar). In RASHT station and SHIRAZ station, TEC exhibits the minimum diurnal variation of TEC in the pre-sunrise hours (03:00 UT) and the maximum values occurred between 09:30 and 12:00 UT. In RASHT station, the highest peak TEC of $\sim 23$ TECU is recorded in April (spring season) and the maximum TEC value of $\sim 10$ TECU at about 09:30 UT is recorded in De-

\section{Conclusion}

This work investigates an ANN model to predict TEC values in 5 GPS stations over IRAN using 50 neurons in a single hidden layer. In the beginning, the Bernese software is used to produce TEC values since the Global TEC Maps have a low precision and resolu-

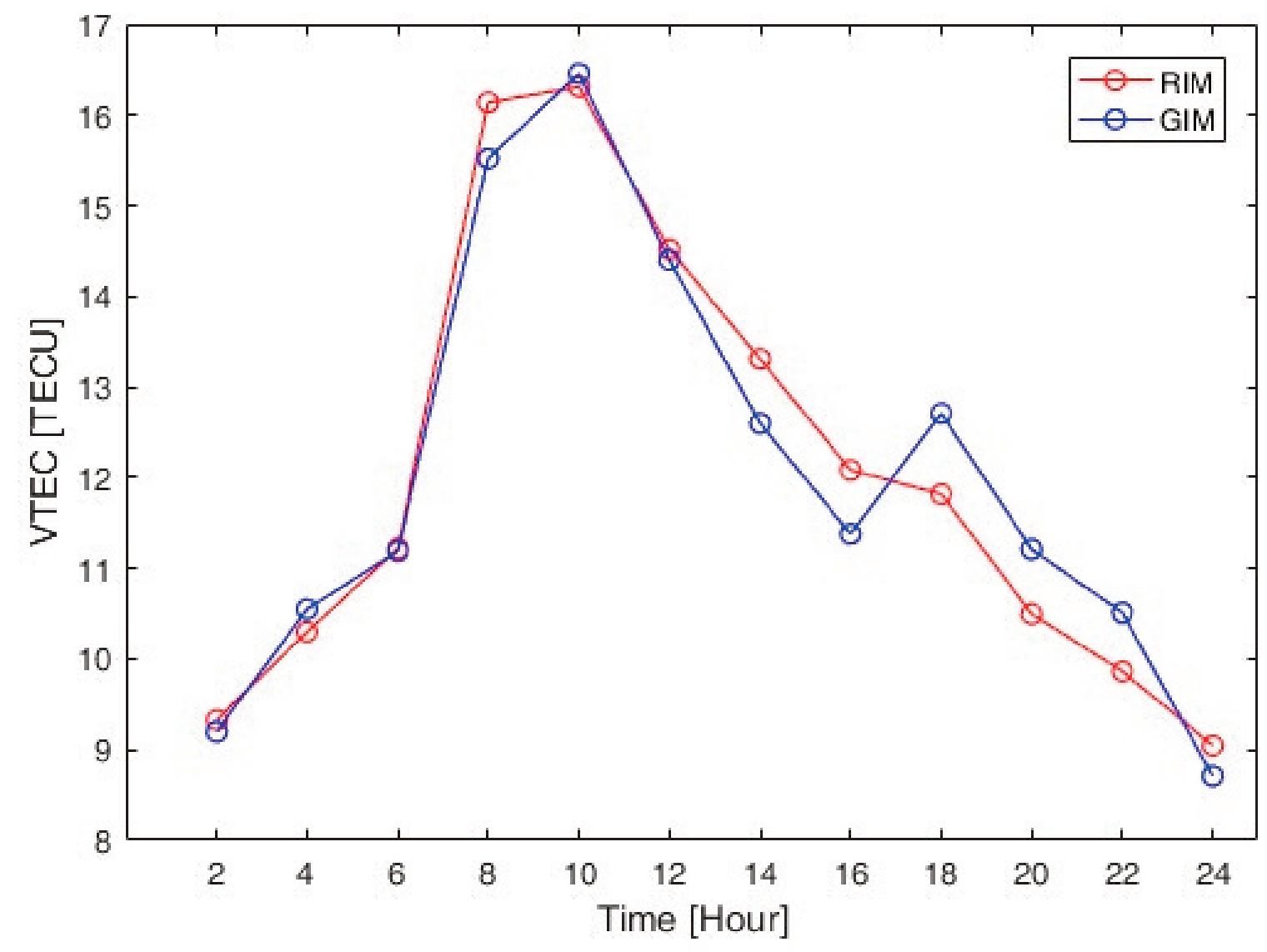

Figure 11. Changing Procedure of Monthly Mean TEC over RASHT Station at Different Hours in 2006.

cember (winter season). In SHIRAZ station, the highest peak TEC of $\sim 32$ TECU is recorded in April and the Peak TEC of $\sim 14$ TECU at about 11:00 UT is recorded in December. tion which are often imperfect to study or describe detailed features of the regional ionosphere. Afterward, the parameters influencing the ionospheric TEC is studied, chosen as the input space elements of NN. In this 
study, the input spaces of $\mathrm{NN}$ are the day number (DN), the hour (HR), the geographical location of the GPS receivers, a 4-month mean of the daily sunspot number (R4), and the mean of the previous eight 3-hourly magnetic A index values (A8).

Considering a single station, the input space of the neural network is reduced to seven parameters namely the year number, the solar activity (R4), the magnetic activity (A8), the seasonal variation (DNS and DNC) and the diurnal variation (HRS and HRC).

To search the potency and capability of NN model for predicting TEC, the RMSE and R2 values are computed and compared with TEC extracted from the IRI2012 model. The result shows that the mean RMSE of $\mathrm{NN}$ model is approximately less than 1 TECU and the $\mathrm{R}^{2}$ of NN model is close to 1 or more than 0.9 at every station on the solstice and equinox days.

As explained in previous sections, if the $\mathrm{R}^{2}$ is more than 0.9 then it can be concluded that the performance of the model is highly acceptable.

The IRI-2012 model is not suitable for calculating and providing TEC over IRAN regions, because there is no global GPS station and ionospheric measurement tools such as Ionosonde, satellite, etc. The IRI-2012 model overestimates the TEC as shown in all the comparisons. Also, the TEC values were compared in two stations with different latitudes located in RASHT and SHIRAZ. As it was shown, the TEC values at lower latitudes (nearest to the equator) are greater than the TEC values at higher latitudes. Hence, the strong ionospheric layer is created in the equatorial region. Furthermore, areas close to the equator have more free electrons and greater TEC values. During the months of April, May, and June, the TEC values are maximum in comparison with other months.

\section{References}

Barrile, V., Cacciola, M., Cotroneo, F.,(2006), Multipath Reduction of GPS Measures through Heuristic Techniques of Compensation", Progress In Electromagnetic Research Symposium 2006, Cambridge, USA, pp. 528-532.

Bilitza, D., Reinisch, B.W.,(2008), International Reference Ionosphere 2007: Improvements and new parameters, Adv. Space Res., 42, 4, 599-609 doi:10.1016/j.asr.2007.07.048.

Bilitza, D., (2001), International reference ionosphere 2000, Radio Sci., 36(2), 261-275.

Bishop, C.M., (1995), Neural Networks for Pattern Recognition, Oxford University Press Inc.,New York.

Cander, R., (1998), Artificial neural network applications in ionospheric studies. Annali di Geofisica 41(5-
6):827-842

Coster, AJ., Foster, J., Erickson, P., (2003), Monitoring the Ionosphere with GPS. Space Weather GPS World 14(5):42-49.

Dach, R., Lutz, S., Walser, P., Fridez(Eds), P., (2015), Bernese GNSS Software Version 5.2. User manual, Astronomical Institute, University of Bern, Bern Open Publishing. DOI: 10.7892/boris.72297; ISBN: 978-3-906813-05-9.

Dow, J. M., Neilan, R. E., Rizos, C., (2009), The International GNSS Service in a changing landscape of global navigation satellite systems, J. Geod., 83, 191-198.

Drossu, R., Obradovic, Z., (1996), Rapid Design of Neural Networks for Time Series Prediction, IEEE Computational Science \& Engineering, Summer 1996, 78-89.

Ghaffari Razin, M.R., Voosoghi, B., Mohammadzadeh, A., (2015), Efficiency of artificial neural networks in map of total electron content over Iran, Acta Geodaetica et Geophysica Hungarica, Springer, 2213-5812.

Gao, Y., Liao, X., Liu, ZZ., (2002), Ionosphere modeling using carrier smoothed ionosphere observations from a regional GPS network, Geomatica 56(2):97-106.

El-naggar, Aly M., (2013), Artificial neural network as a model for ionospheric TEC map to serve the single frequency receiver, Alexandria Engineering Journal 52, 425-432.

Farzaneh, S., Forootan, E., (2018). Reconstructing Regional Ionospheric Electron Density: A Combined Spherical Slepian Function and Empirical Orthogonal Function Approach.Surveys in Geophysics, 39(2), 289-309, https:/ / doi.org/10.1007/s10712-017-9446y.Fausett, L., (1994), Fundamentals of neural networks: architectures, Algorithms, and Applications, Prentice Hall, New Jersey.

Haykin, S., (1994), Neural networks, a comprehensive foundation, Macmillan College Publishing Company.

Habarulema, J. B., McKinnell, L. A. and Cilliers, P. J., (2007), Prediction of global positioning system total electron content using neural networks over South Africa, J. Atmos Solar Terr. Phys., 69, 1842-1850.

Habarulema, J. B., L. A. McKinnell, P. J. Cilliers, and B. D. L. Opperman, (2009a), Application of neural networks to South African GPS TEC modeling, Adv. Space Res., 43(11), 1711-1720.

Habarulema, J. B., McKinnell, L.-A., and Opperman, B. D. L., (2009b), Towards a GPS-based TEC prediction model for Southern Africa with feed forward 
networks, Advances in Space Research,44(1), 82-92. Hill, T., Marquez, L., Oconnor, M. and Remus, W., (1994), Artificial neural network models for forecasting and decision making, International Journal of Forecasting, 10, p. 5 .

Hirooka, S., Hattori K., Takeda T., (2011), Numerical validations of neural-network-based ionospheric tomography for disturbed ionospheric conditions and sparse data. Radio Sci. doi:10.1029/2011RS004760.

Hofmann-Wellenhof, B., Lichtenegger H. and Collins J., (1992), Global Positioning System Theory and Practice, Springer-Verlag Wien New York.

Liu, J., Chen, R., Wang, Z., Zhang, H., (2011), Spherical cap harmonic model for mapping and predicting regional TEC, GPS Solution,15, 109-119.

Kelley, MC., (1989), The earths ionosphere: plasma physics and electrodynamics. Academic Press Inc, Massachusetts.

Leandro, R. F. and Santos, M. C., (2007), A neural network approach for regional vertical total electron content modelling, Studia Geophysica et Geodaetica, 51, 279-292.

Liu, Z., Gao, Y., (2003), Ionospheric TEC predictions over a local area GPS reference network. GPS Solut 8(1):23-29

Klobuchar, J., (1987), Ionospheric Time-Delay Algorithms for Single-Frequency GPS Users. IEEE Transactions on Aerospace and Electronic Systems (3), pp. 325-331.

Klobuchar, J., (1991), Ionospheric Effects on GPS, Reprinted from GPS World.

Klobuchar, JA., (1975), A first-order worldwide ionospheric time delay algorithm. Air Force Cambridge Research Laboratories, Hanscom, AFB, MA, AFCRL-TR-75-0502, AD A018862.

Komjathy, A., Langley, RB.,(1996), An assessment of predicted and measured ionospheric total electroncontent using a regional GPS network. Proceedings of the National Technical Meeting of the Institute of Navigation, pp 615-624.

McKinnell, L.A., and Poole A.W.V., (2001), Ionospheric variability and electron density profile studies with neural networks, Adv. Space Res., 27, 1, pp.83-90.

McKinnell, L. A. and Poole, A.W. V., (2000), The development of a neural network based short term foF2 forecast program, Adv. Space Res., 25(4), 287-290.

McKinnell, L. A., (2008), Using neural networks to determine the optimum solar input for the prediction of ionospheric parameters, Adv. Space Res., 42, 634-638.

Maruyama, T., (2007), Regional reference total electron content model over Japan based on neural network mapping techniques, Ann. Geophys., 25, 2609-2614. Mittal, GS., Zhang J., (2000), Prediction of temperature and moisture content of frankfurters during thermal processing using neural network, Meat Sci. 55: 13-24.

Meggs, R., (2005), Mapping of ionospheric total electron content using global navigation satellite systems, Ph.D. thesis, University of Bath, Bath, UK.

Moon, Y., (2004), Evaluation of 2-dimensional ionosphere models for national and regional GPS networks in Canada. Master's thesis, University of Calgary, Calgary

Opperman, B. D. L., Cilliers, P. J., McKinnell, L.-A. and Hag-gard, R., (2007), Development of a regional GPS-based Ionospheric TEC model for South Africa, Advances in Space Research, 39(5),808-815.

Rothacher, M., Beutler, G., Brockmann, E., Mervart, L., Schaer, S., Springer, T.A., Wild, U., Wiget, A., Boucher, C., Seeger, H., (1996a), Annual Report 1995 of the CODE Analysis Center of the IGS, Astronomical Institute, University of Berne.

Rumelhart, DE., Hinton GE., and Williams RJ., (1986), Learning internal representation by back-propagation errors. In: Rumelhart DE, McClelland JL, the PDP Research Group(Eds.), Parallel Distributed Processing: Explorations in the Microstructure of Cognition. MIT Press, MA.

Sayin, I., Arikan F, Arikan O., (2008), Regional TEC mapping with random field priors and Kriging. Radio Sci.doi:10.1029/2007RS003786.

Schaer, S., (1999), Mapping and Predicting the Earth's Ionosphere Using the Global Positioning System, Ph.D thesis, Astronomical Institute, University of Berne, Switzerland.

Seeber, G., (2003), Satellite Geodesy: foundations methods and applications. Walter de Gruyter, Berlin and New York.

Shene, C., Andrews, B. and Asenjo, A. J., (1998), Optimization of Bacillus subtilis for the fed-batch fermentations for the maximization of the synthesis of a recombinant b -1, 3-glucanase, Computer Applications in Bio-technology, Japan, vol. CAB 7, p. 219

Skone, S., (1998), Wide area ionosphere grid modelling in the auroral region, Ph.D. thesis, University of Calgary, Department of Geomatics Engineering, Calgary, Alberta, Canada.

Schaer, S., (1999), Mapping and predicting the earths ionosphere using the global positioning system. PHD dissertation, Astronomical Institute, University of Berne.

Sharifi, M. A., Farzaneh, S., (2017). The ionosphere electron density spatio-temporal modeling based on the 
Slepian basis functions. Acta Geodaetica et Geophysica, 52(1), 5-18.

Sharifi, M. A., Farzaneh, S., (2016). Local Ionospheric Modeling Using the Localized Global Ionospheric Map and Terrestrial GPS. Acta Geophysica, 64(1), 237-252.

Shene, C., Andrews, B. and Asenjo, A. J., (1999), Fedbatch optimizations of Bacillus subtilis fed-batch ToC46 (pPFF1) for the synthesis of a recombinant $b$ -1, 3-glucanase: Experimental study and modelling, Enzyme and Microbial Technology, 24, p. 247.

Savkovic-Stevenovic, J., (1994), Neural networks for process analysis and optimization: modelling and applications, Computers in Chemical Engineering, 18, (11-12), p 1149 .

Schaer, S., Beutler, G., Rothacher, M., (1998), Mapping and predicting the ionosphere, paper presented at 1998 IGS Analysis Center Workshop, Int. GNSS Serv., Darmstadt, Germany, 9 - 11 Feb.

Schaer, S., Markus, R., Gerhard, B. and Timon,A. S., (1996), Daily global ionosphere maps based on GPS carrier phase data routinely produced by the CODE Analysis Center, Proceeding of the IGS Analysis Center Workshop, Silver Spring, Maryland, pp. 181192, USA.

Simpson, PK., (1990), Artificial neural systems: foundations, paradigms, applications, and implementations.Pergamon Press, New York.

Tulunay, E., Senalp, E. T., Cander, L. R.,Tulunay, Y. K., Bilge, A. H., Mizrahi, E., Kouris, S. S. and Jakowski, N., (2004), Development of algorithms and software for forecasting now casting and variability of TEC. Ann. Geophys., 47(2/3), 1201-1214.

Tulunay, E., Senalp, E. T., Radicella, S. M. and Tulanay, Y., (2006), Forecasting total electron content maps by neural network technique, Radio Science, 41, doi:10.1029/2005RS003285.

Venkata Ratnam, D., Venkata Dinesh, B., Tejaswi, B., Praveen Kumar, D., Ritesh, T.V., Brahmanadam, P.S., Vindhya, G., (2012), TEC prediction model using neural networks over a Low Latitude GPS Station, International Journal of So ft Computing and Engineering (IJSCE)ISSN: 2231 - 2307, Volume - 2, Issue - 2.

Watthanasangmechai, K., Supnithi, P., Lerkvaranyu, S. and Maruyama, T., (2010), Hourly and seasonal TEC prediction with neural network at Chumphon equatorial lattitude station, Thailand, Proceeding of the 25th International Technical Conference on Circuits/Systems, Computer and Communications (ITC-CSCC), Pattaya, Thailand.

Watthanasangmechai, K., Supnithi, P., Lerkvaranyu, S., Tsugawa, T., Nagatsuma,T., Maruyama, T., (2012),
TEC prediction with neural network for equatorial latitude station in Thailand, Proceeding of the Earth Planets Space, 64, 473-483.

Wienia R. J., (2008), Use of Global Ionospheric Maps for Precise Point Positioning, Msc Scriptie, Delft University of Technology.

Yilmaz, A., Akdogan, K. E. and Gurun, M., (2009), Regional TEC mapping using neural networks, Radio Science, 44, RS3007, doi.org/10.1029/2008RS004049.
*Corresponding author: Saeed Farzaneh, School of Surveying and Geospatial Engineering, College of Engineering, University of Tehran, Tehran, Iran email: Farzaneh@ut.ac.ir

(C) 2018 by the Istituto Nazionale di Geofisica e Vulcanologia. All 